\title{
Serum Immunoglobulin E Levels in Patients with Allergic Conjunctivitis and Contact Lens Wearers
}

\author{
Ozlem Gurses Sahin, ${ }^{1}$ Nusret Taheri ${ }^{2}$ \\ ${ }^{1}$ Department of Ophthalmology, and ${ }^{2}$ Department of Biochemistry, Middle East Technical \\ University Health Center, Ankara, Turkey
}

\begin{abstract}
Aim: To determine the differences between total and serum-specific immunoglobulin E levels in patients with type 1 allergic conjunctivitis and asymptomatic contact lens wearers. The correlation of total serum immunoglobulin E level of asymptomatic contact lens wearers with contact lens wearing time, and total duration of contact lens use was also evaluated.

Methods: This was a case-control study involving 25 asymptomatic contact lens wearers, 25 patients with type 1 allergic conjunctivitis, and 25 age-and sex-matched healthy controls. Total serum immunoglobulin $E$ levels were detected by enzyme-linked immunosorbent assay. Serum-specific IgE analysis against the listed indoor, food, and outdoor allergens were studied by immunofluorescence assay for participants whose total serum immunoglobulin E levels were $>100 \mathrm{IU} / \mathrm{mL}$. Pearson's and Spearman's correlations were used for bivariate analysis. Statistical significance was accepted at the 0.05 level.

Results: The mean level of total serum immunoglobulin E was greater for patients with type 1 allergic conjunctivitis than for contact lens wearers and controls. Serum-specific immunoglobulin E detected in patients with type 1 allergic conjunctivitis was against indoor, food, and outdoor allergens, while serum-specific immunoglobulin $E$ detected in contact lens wearers was only against outdoor allergens. A statistically significant correlation was found for total serum immunoglobulin E levels of contact lens wearers with contact lens wearing time.

Conclusions: These results suggest that differences in serum total and specific immunoglobulin E levels exist between patients with type 1 allergic conjunctivitis and CL wearers and controls. Further research in a larger group of patients is needed to validate these findings.
\end{abstract}

Key words: Case-control studies, Conjunctivitis, allergic, Contact lenses, Immunoglobulins

Asian J Ophthalmol. 2011;12:152-5.

\section{Introduction}

Allergy is considered to be a state of immune dysregulation from $T$ helper 1 (Th1)- and Th2-cell balance, and this state leads to overproduction of immunoglobulin $(\mathrm{lg}) \mathrm{E}$, which plays a central role in the pathogenesis of atopic diseases. ${ }^{1}$ Allergen-specific IgE production is regarded as the key event, and increase in serum-specific $\lg E$ is considered to be an indicator of type 1 hypersensitivity response. ${ }^{2}$ Seasonal and perennial allergic conjunctivitis (SAC and PAC) are the only ocular diseases to involve solely type I hypersensitivity. ${ }^{3}$

Correspondence: Dr Ozlem Gurses Sahin, Department of

Ophthalmology, Middle East Technical University, Ataturk Sitesi, Hayrı Cecen Sokak 29/10, Oran, Ankara 06450, Turkey.

Tel: (90 312) 2104987 ;

E-mail: ozlem1158@yahoo.com

This study was presented as a poster at the Association for Research in Vision and Ophthalmology Annual Meeting, Fort Lauderdale, Florida, USA, 3-7 May 2009.
The other main forms of allergic conjunctivitis, vernal and atopic keratoconjunctivitis, have a more complex immunological basis and a chronic inflammatory component. ${ }^{3}$ Ocular surface changes induced by contact lens (CL) wear and deposit build-up on $\mathrm{CL}$ surfaces have been implicated in inducing an ocular hypersensitivity response in relation to $\mathrm{CL}$ wear. ${ }^{4}$

The purpose of this study was to determine the differences in total and serum-specific lgE levels in patients with type 1 allergic conjunctivitis, asymptomatic CL wearers, and age- and sexmatched healthy controls. The correlation of total serum IgE level in asymptomatic $\mathrm{CL}$ wearers with $\mathrm{CL}$ wearing time and total duration of $\mathrm{CL}$ use was also evaluated.

\section{Methods}

This was a retrospective case-control study involving 25 asymptomatic CL wearers, 25 patients with type 1 allergic conjunctivitis, 
and 25 age- and sex-matched healthy controls. The participants were enrolled according to the principles of the Declaration of Helsinki and ethics committee approval was obtained. Written informed consent was obtained from all patients.

Patients with allergic conjunctivitis had been diagnosed with either SAC or PAC according to their past medical history. They had clinical symptoms of itching, redness, and tearing, and clinical signs of injection of conjunctival vessels and mild to moderate papillary reaction in the palpebral conjunctiva. They had not been receiving any systemic or topical antiallergic treatment and had not previously used CL.

CL wearers had been using conventional hydrogel lenses for a minimum of 6 hours/day for a minimum duration of 6 months. The eyelids of $\mathrm{CL}$ wearers were examined for the presence of papillae, and all CL wearers had normal slit-lamp examination findings.

The control participants had no ocular pathologies other than refractive errors. They had 20/20 vision with ametropia of $<3 D$,

Table 1. Indoor, food, and outdoor allergens tested for in patients with type 1 allergic conjunctivitis, asymptomatic contact lens wearers, and control participants.

\begin{tabular}{|lc|}
\hline Indoor and food allergens & Outdoor allergens \\
\hline Egg white & Populus salix \\
Egg yolk & Eucalyptus \\
Cow's milk & Quercus alba \\
Peanuts & Olea europea \\
Alternaria & Pinus species \\
Aspergillus & Salix lasolepis \\
Candida & Poa pralensis \\
Cladosporium & Artemissa vulgaris \\
Penicillum & Festuca elatior \\
Cat dander & Plantago lancelata \\
Dog dander & Phleum pralense \\
Wheat & Avena sativa \\
Cockroach & Lollium perenne \\
Mite plenory & Alnus glutinosa \\
Mite farienae & Parietarla officinalis \\
\hline
\end{tabular}

and anisometropia of $<1 \mathrm{D}$. None of the control participants had previously used $\mathrm{CL}$. The control participants were otherwise healthy and were not using any topical or systemic medication.

Total serum IgE levels were detected by using enzyme-linked immunosorbent assay. ${ }^{5}$ Serum-specific IgE analysis against indoor, food, and outdoor allergens (Table 1) were studied by using immunofluorescence assay ${ }^{6}$ for participants whose total serum lgE levels were $>100 \mathrm{IU} / \mathrm{mL}$. Luminescence units $(\mathrm{LU})$ were used to classify the allergen concentrations as undetectable, low, medium, or high according to serum-specific lg E level.

Statistical analysis was done by using the Statistical Package for the Social Sciences version 15 for Windows (SPSS Inc, Chicago, USA). Pearson's and Spearman's correlations were used for bivariate analysis. Statistical significance was accepted at the 0.05 level.

\section{Results}

Eight (32\%) patients had PAC, and 17 (68\%) had SAC. CL wearers had been wearing CL for a mean of 10.56 hours/day (SD, 3.39 hours/day; range, 6-24 hours/day), and had been using CL for a mean of 3.32 years (SD, 2.15 years; range, 6 months to 8 years). The demographic characteristics are shown in Table 2.

The mean levels of total serum IgE of patients with type 1 allergic conjunctivitis, CL wearers, and controls were $227.40 \mathrm{IU} / \mathrm{mL}$ $(\mathrm{SD}, 288.60 \mathrm{IU} / \mathrm{mL}$; range, $36-1015 \mathrm{IU} / \mathrm{mL}), 63.68 \mathrm{IU} / \mathrm{mL}(\mathrm{SD}$, $107.09 \mathrm{IU} / \mathrm{mL}$; range, $16-551 \mathrm{IU} / \mathrm{mL}$ ), and $36.36 \mathrm{IU} / \mathrm{mL}$ (SD, 24.98; range, 19-85 IU/mL), respectively. The level of serum-specific lgE detected as LU in patients with type 1 allergic conjunctivitis was high; the most common allergens are shown in Table 3. The level of serum-specific lgE detected as LU in CL wearers was low, and there was no detectable serum-specific lgE in control participants. There was a statistically significant correlation of total serum $\lg \mathrm{E}$ levels in CL wearers with CL wearing time (Pearson's correlation coefficient $=0.863$; Spearman's correlation coefficient $=0.626$;

Table 2. Patients' demographic characteristics and immunoglobulin E levels in patients with type 1 allergic conjunctivitis, asymptomatic contact lens wearers, and control participants.

\begin{tabular}{|c|c|c|c|}
\hline & $\begin{array}{l}\text { Type } 1 \text { allergic } \\
\text { conjunctivitis }\end{array}$ & Contact lens wear & Controls \\
\hline Number of participants & 25 & 25 & 25 \\
\hline \multicolumn{4}{|l|}{ Sex } \\
\hline Male & 11 & 9 & 12 \\
\hline Female & 14 & 16 & 13 \\
\hline \multicolumn{4}{|l|}{ Age (years) } \\
\hline Mean (SD) & $23.88(6.12)$ & $22.92(4.76)$ & $21.72(4.52)$ \\
\hline Range & $17-40$ & $18-38$ & 18-39 \\
\hline \multicolumn{4}{|l|}{ Total serum IgE (IU/mL) } \\
\hline Mean (SD) & $227.40(288.60)$ & 63.68 (107.09) & $36.36(24.98)$ \\
\hline Range & $36-1015$ & $16-551$ & $19-85$ \\
\hline Specific serum $\lg E(L U)$ & High & Low & Undetectable \\
\hline Allergens & Indoor, food, and outdoor & Outdoor & - \\
\hline
\end{tabular}

Abbreviations: $\lg \mathrm{E}=$ immunoglobulin $\mathrm{E} ; \mathrm{LU}=$ luminescence unit. 
Table 3. Indoor, food, and outdoor allergens in patients with type 1 allergic conjunctivitis and asymptomatic contact lens wearers.

\begin{tabular}{|lll|}
\hline & Indoor and food allergens & Outdoor allergens \\
\hline Seasonal allergic conjunctivitis & & $\begin{array}{l}\text { Festuca elatior, Poa pralensis, Pinus, Phleum pralense, } \\
\text { Plantago lancelata, Lollium perenne }\end{array}$ \\
Perennial allergic conjunctivitis & $\begin{array}{l}\text { Cat and dog dander, Cockroach, Mite plenory, Mite farienae, } \\
\text { Aspergillus, Cladosporium, Cow's milk, Wheat }\end{array}$ & Artemisia vulgaris, Parietarla officinalis, Poa pralensis, Salix \\
& & lasolepis, Populus salix, Pinus
\end{tabular}

Figure 1. Correlation of total serum immunoglobulin E level of asymptomatic contact lens wearers with contact lens wearing time.

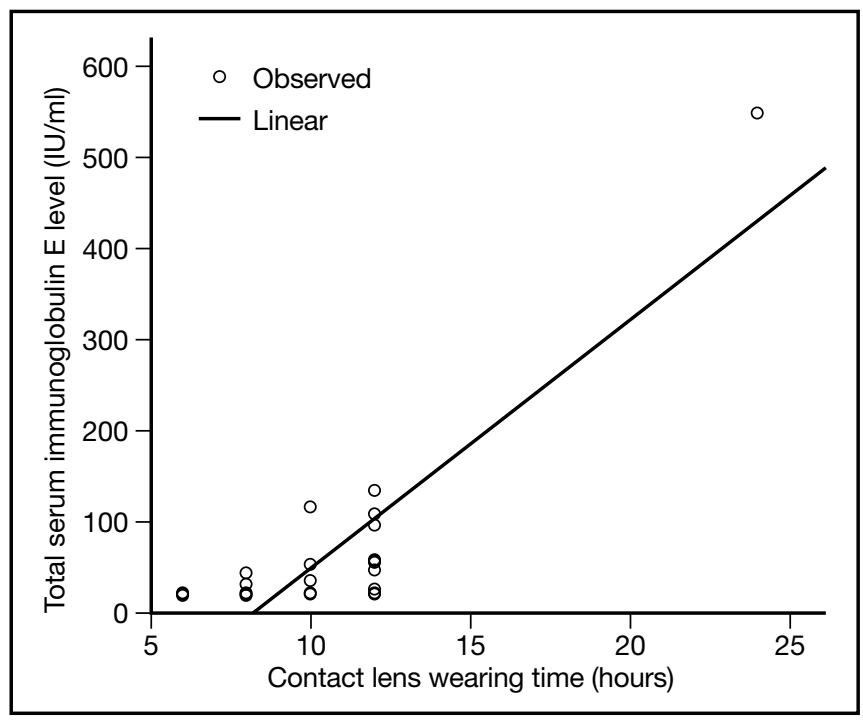

correlation is significant at the 0.01 level) [Figure 1]. No significant correlation was found between duration of $\mathrm{CL}$ use and total serum IgE level (Pearson's correlation coefficient $=0.092$; Spearman's correlation coefficient $=0.044$; correlation is not significant at the 0.05 level).

\section{Discussion}

SAC and PAC are the most common forms ocular allergic disorders that are primarily lgE-mediated, and share features in common with other atopic conditions. ${ }^{7}$ PAC appears to be an extension of SAC in that both conditions show increased $\mathrm{TH} 1 / \mathrm{TH} 2$ cytokine ratios, increased expression of adhesion molecules, mast cell activation, and release of mediators, particularly histamine, which appear to play an integral role in the inflammatory process. ${ }^{8}$ In contrast, vernal keratoconjunctivitis and atopic keratoconjunctivitis are complex diseases, involving both early- and late-phase allergic responses, and are characterised by severe chronic immune inflammation with T-cell infiltration in the conjunctiva. ${ }^{9}$

In this study, patients with type 1 allergic conjunctivitis, either SAC or PAC, were selected because of their common pathogenesis, which is also shared by the ocular hypersensitivity response to $\mathrm{CL}$ wear. Tear IgE is considered to be a product of local synthesis, ${ }^{10}$ and its level has been shown to increase during an acute event of CL-induced papillary conjunctivitis. ${ }^{10,11}$ Ocular surface changes induced by $\mathrm{CL}$ wear have been classified as subclinical conjunctival inflammation rather than an acute event in healthy asymptomatic $\mathrm{CL}$ wearers. ${ }^{4}$ Subclinical conjunctival inflammation in healthy asymptomatic $\mathrm{CL}$ wearers might increase total and serum-specific $\lg \mathrm{E}$ levels, rather than locally synthesized tear IgE level. Since healthy $\mathrm{CL}$ wearers have normal tarsal conjunctivae without the presence of papillae, they remain asymptomatic despite the elevations in total and serum-specific lgE levels. Decreased mucin production from conjunctival goblet cells and non-goblet epithelial cells might be an important risk factor for development of the symptoms.

This study compared the differences in total and serum-specific $\lg E$ levels between patients with type 1 allergic conjunctivitis, including SAC and PAC, and healthy asymptomatic CL wearers. Patients with SAC have been reported to show the highest positivity rate for specific allergens, including grass and tree pollens. ${ }^{12}$ Patients with PAC have been shown to have high sensitivity to indoor antigens such as house dust mite. ${ }^{13}$ The mean serum $\lg \mathrm{E}$ level has been shown to be more highly elevated in patients with allergic conjunctivitis than in healthy asymptomatic $\mathrm{CL}$ wearers and those with CL-related papillary conjunctivitis. ${ }^{10}$ This study showed a greater increase in mean total serum lgE level in patients with type 1 allergic conjunctivitis than in healthy asymptomatic $\mathrm{CL}$ wearers and controls. This study also found an increase in serum-specific $\operatorname{lgE}$ of patients with SAC against outdoor allergens, including tree and grass pollens such as pinus species, festuca elatior, poa pralensis, phleum pralense, plantago lancelata, and lollium perene. The increase in serum-specific lgE of patients with PAC was mostly against indoor and food allergens, including cat and dog dander, cockroach, mite plenory, mite farienae, aspergillus, cladosporium, cow's milk, and wheat. The increase in serum specific lgE level for healthy asymptomatic $\mathrm{CL}$ wearers was lower than that for patients with SAC and PAC, and was found to be only against outdoor allergens rather than food and indoor allergens. The most common outdoor allergens for healthy asymptomatic $\mathrm{CL}$ wearers were similar to those for patients with SAC, and included grass and tree pollens such as artemisia vulgaris, parietarla officinalis, poa pralensis, salix lasolepis, populus salix, and pinus species. Environmental factors 
have been suggested to cause ocular surface symptoms such as ocular irritation, discomfort, and dryness in CL wearers. ${ }^{14}$ This study also found sensitisation to outdoor allergens in CL wearers. Conjunctival cytological changes by impression cytology have been reported in asymptomatic CL wearers, and the intensity of the cytological changes have been related to the $\mathrm{CL}$ wearing time..$^{15}$ This study is the first to show a statistically significant correlation between total serum IgE level of healthy asymptomatic CL wearers and daily $\mathrm{CL}$ wearing time. However, no significant correlation was found between the duration of $\mathrm{CL}$ use and total serum lgE level of healthy $C L$ wearers. CL might trap outdoor allergens at increased concentrations, thus being an inciting factor for elevated serum IgE levels in this group. Unfortunately, this study did not look for allergens trapped on the $\mathrm{CL}$. Frequent removal and cleaning of $\mathrm{CL}$ is recommended, and individuals should be tested for total serum $\lg \mathrm{E}$ level prior to $\mathrm{CL}$ wear.

These results suggest that differences in serum total and specific lgE levels exist between patients with type 1 allergic conjunctivitis, including SAC and PAC, and healthy asymptomatic $\mathrm{CL}$ wearers. Total serum IgE levels were greater in patients with type 1 allergic conjunctivitis than in healthy asymptomatic CL wearers or control participants. There was a statistically significant linear correlation between total serum lgE levels in healthy $\mathrm{CL}$ wearers and daily $\mathrm{CL}$ wearing time. However, this study included a relatively small number of patients, and further research in a larger group of patients is needed to validate the findings of this study.

\section{References}

1. Lacour M. Acute infections in atopic dermatitis a clue for a pathogenic role of a Th1/Th2 imbalance. Dermatology. 1994;188: 255-7.

2. Rance HA, Albero R. Comparison of results of skin tests, RAST, and double-blind, placebo-controlled food challenges in children with atopic dermatitis. J Allergy Clin Immunol. 1984;74:26-33.

3. Trocme SD, Sra KK. Spectrum of ocular allergy. Curr Opin Allergy Clin Immunol. 2002;2:423-7.

4. Pisella PJ, Malet F, Lejeune S, et al. Ocular surface changes induced by contact lens wear. Cornea. 2001;20:820-5.

5. Van Knapen F, Franchimont JH, Verdonk AR, et al. Detection of specific immunoglobulins (IgG, IgM, IgA, IgE) and total IgE levels in human trichinosis by means of the enzyme-linked immunosorbent assay (ELISA). Am J Trop Med Hyg. 1982;31:973-6.

6. Kim TE, Park SW, Cho NY, et al. Quantitative measurement of serum allergen-specific IgE on protein chip. Exp Mol Med. 2002; 34:152-8.

7. Anderson DF, MacLeod JD, Baddeley SM, et al. Seasonal allergic conjunctivitis is accompanied by increased mast cell numbers in the absence of leucocyte infiltration. Clin Exp Allergy. 1997; 27:1060-6.

8. Leonardi A, De Dominicis C, Motterle L. Immunopathogenesis of ocular allergy: a schematic approach to different clinical entities. Curr Opin Allergy Clin Immunol. 2007;7:429-35.

9. Leonardi A, Motterle L, Bortolotti M. Allergy and the eye. Clin Exp Immunol. 2008;153:17-21.

10. Barishak Y, Zavaro A, Samra Z, et al. An immunological study of papillary conjunctivitis due to contact lenses. Curr Eye Res. 1984; 3:1161-8.

11. Zhao Z, Fu H, Skotnisky CC, et al. IgE antibody on worn highly oxygen-permeable silicone hydrogel contact lenses from patients with contact lens-induced papillary conjunctivitis (CLPC). Eye Contact Lens. 2008;34:117-21.

12. Mimura $\mathrm{T}$, Amano $\mathrm{S}$, Funatsu $\mathrm{H}$, et al. Correlations between allergen-specific IgE serum levels in patients with allergic conjunctivitis in spring. Ocul Immunol Inflamm. 2004;12:45-51.

13. Dart JK, Buckley RJ, Monnickendan M, et al. Perennial allergic conjunctivitis: definition, clinical characteristics and prevalence. A comparison with seasonal allergic conjunctivitis. Trans Ophthalmol Soc UK. 1986;105:513-20.

14. Begley CG, Chalmers RL, Mitchell GL, et al. Characterization of ocular surface symptoms from optometric practices in North America. Cornea. 2001;20:610-8.

15. Tomatir DK, Erda N, Gürlü VP. Effects of different contact lens materials and contact lens-wearing periods on conjunctival cytology in asymptomatic contact lens wearers. Eye Contact Lens. 2008;34:166-8. 